\title{
Epistemically Self-defeating Arguments and Skepticism about Intuition
}

\author{
Paul Silva Jr. \\ $<$ psilvajr@gmail.com>
}

April 19, 2015

\begin{abstract}
An argument is epistemically self-defeating when either the truth of an argument's conclusion or belief in an argument's conclusion defeats one's justification to believe at least one of that argument's premises. Some extant defenses of the evidentiary value of intuition have invoked considerations of epistemic self-defeat in their defense. I argue that there is one kind of argument against intuition, an unreliability argument, which, even if epistemically self-defeating, can still imply that we are not justified in thinking intuition has evidentiary value.
\end{abstract}

\section{Intuition and Epistemic Self-Defeat}

Let us say an argument is epistemically self-defeating when either the truth of an argument's conclusion or belief in an argument's conclusion defeats one's justification to believe at least one of that argument's premises. ${ }^{1}$ Accordingly, unless one has some other source of justification for the conclusion of such an argument one lacks justification to believe that conclusion. We are not unfamiliar with such arguments. Take any argument $\Gamma$ whose conclusion is that we cannot have justification to believe anything. Any such argument

\footnotetext{
${ }^{1}$ This should be restricted to essential premises, where such premises are ones that are needed if the premise set is to evidentially support the conclusion.
} 
must be epistemically self-defeating, for if $\Gamma$ 's conclusion is true or if we happen to believe it then we lack justification to believe any of $\Gamma$ 's premises. $^{2}$

Considerations of epistemic self-defeat constitute an essential ingredient in some extant defenses of intuition and its role in philosophical thought and theorizing. For example, Joel Pust has argued that certain attempts to argue against the evidential worth of intuitions are bound to be self-defeating because they include as a premise an epistemological principle whose justification itself seems to rely on the evidentiary value of our intuitions. ${ }^{3}$ But this would defeat one's justification to believe the conclusion of such an argument against intuitions. ${ }^{4,5}$ George Bealer has argued that it's epistemically self-defeating to reject the evidentiary value of intuitions for it is by our intuitions (alone) that we are able to make basic epistemic classifications integral to any theorizing. That is, we rely on intuitions to determine what counts as an experience, an observation, a theory, an explanation, a simple explanation, a law of nature, a deductively valid argument, a logical truth, a theoretical virtue, etc. Thus, any theory that makes these basic epistemic classifications and yet rejects the evidentiary value of intuitions will itself be unjustified. ${ }^{6}$ As a final example, Laurence BonJour argues that in order for

\footnotetext{
${ }^{2}$ Being epistemically self-defeating is not a monadic property of arguments; it's a relation between thinkers and arguments. An argument whose conclusion is 'the author of this paper is not justified in believing anything' is epistemically self-defeating for this paper's author only, not its readers. Also, there are other ways for an argument to be epistemically self-defeating that I will not be discussing. For instance, an argument's conclusion can call into question the form of inference the argument exemplifies, or it can call into question one's ability to reliably make such inferences, or a conclusion can be a self-defeating proposition ('this proposition is unjustified' or ' $p$ and I am not justified in believing $\left.p^{\prime}\right)$.

${ }^{3}$ By speaking of intuitions having evidential value or worth I mean that intuitions are a source of evidence that justify beliefs.

${ }^{4}$ The epistemological principle Pust attacks is this: "Aside from propositions describing the occurrence of her judgments, $\mathrm{S}$ is justified in believing only those propositions which are part of the best explanation of S's making the judgments that she makes." See Pust [2001, 236, 249-51].

${ }^{5}$ Michael Huemer [2007, 39-41] has argued along similar lines, though in defense of the more general claim that seemings of all sorts have evidential worth (intuitions are just one kind of seeming according to Huemer). For in order to reject the evidential worth of seemings, says Huemer, it is a contingent fact that one will end up epistemically basing their opposition to seemings on seemings. Thus, those who deny that seemings have evidential worth "are in a self-defeating position, in that their views cannot be both true and justified," (30).

${ }^{6}$ Bealer $[1992,104-108,119 \mathrm{ff}]$. Bealer's point is not so much that an argument is self-
} 
one to have justification to believe the conclusion of an argument one must have a reason to think that the conclusion is true or else likely to be true if the premises are true. But intuition alone is fit to give us such a reason. Thus, any (non-question begging) argument against the evidential value of intuition must presuppose its epistemic worth, thereby making arguments against intuition epistemically self-defeating. ${ }^{7,8}$

Defending intuition after this manner has the structure of a reductio: the intuition defender provisionally grants his opponent's premises but then goes on to show that if the conclusion is true some badness follows, where the badness at issue forms a central aspect of the defender's defense against his opponent. In each of the three cited cases, the badness at issue is epistemic self-defeat. And the upshot of establishing that one's opponent uses a selfdefeating argument is that such arguments fail to give anyone a reason to accept their conclusion.

However successful appeals to epistemic self-defeat might be elsewhere, there is one kind of argument against intuition where considerations of selfdefeat cannot provide an adequate defense of intuition. This kind of argument moves from the premise that intuition is not reliable to the conclusion that we should not treat it as a source of evidence that justifies beliefs. What we will see is that the Bealer-BonJour-Pust reductio strategy fails to sufficiently defend intuition against this type of argument even if it is epistemically selfdefeating.

defeating, but that a given epistemological position (namely, an empiricism that rejects intuitions) is epistemically self-defeating in the sense that if it were true, we would not be justified in believing it. Nevertheless, Bealer's thesis clearly implies that any argument against intuition which employs premises that make use of any basic epistemic classification will be an epistemically self-defeating argument. For convenience, in this essay I will speak as though Bealer's concern was with epistemically self-defeating arguments.

${ }^{7}$ BonJour [1998, 4-6]. BonJour does not often use the term 'intuition', preferring instead the term 'rational insight' to designate our source of a priori justification. See BonJour [1998, 102]. Note also the higher-order requirement on inferential justification that BonJour presupposes: it is not enough that an inference makes the conclusion likely to be true or that one competently employ such an inference, one must also have reason to think that the inference at least makes the conclusion likely to be true. Externalists of various sorts will buck such stipulations.

${ }^{8}$ Each of these authors take intuition to be a source of a priori justification. However, not all agree with this view of intuition. (See Kornblith [2002, 7-8] and Devitt [2010, 292].) This issue is of marginal relevance here, for all that Bealer, BonJour, and Pust need to run the arguments summarized above is that intuition be a source of justification; it does not matter what type of justification it yields. 
To evaluate this kind of unreliability argument I will proceed after the Bealer-BonJour-Pust fashion of granting the key premises and then showing how epistemic self-defeat might be generated by an argument that employs them. But the upshot will not be a defense of intuition-or at least not a complete defense of intuition. For in the course of defending intuition by appeal to epistemic self-defeat the defender will have (provisionally) granted theses that lead straightaway into skepticism about the evidentiary value of intuitions.

\section{Epistemic Self-Defeat and the Unreliability Argument}

Before proceeding to the argument against intuition some clarifying remarks are needed. For the purposes of this essay 'intuition' names a general type of contentful mental state. This understanding of the term 'intuition' should be understood as distinct from our use of the terms 'intuitions' and the locutions 'has an intuition that' and 'intuits that' which refer to the contents of tokens of that general type of mental state.

Characterizing the general type of state we're calling intuition is a bit of a trick. At bottom, each tokening of this type involves a specific propositional content wherein that content seems true to the thinker realizing the state. Many agree on this point, but as we look for further clarification controversy ensues. ${ }^{9}$ Let us sidestep the controversy, stipulating that we are to understand intuition to be a contentful mental state wherein a proposition seems true, independently of introspection, sense perception, memory, testimony, and inference. This stipulation will not hamper the present inquiry for the arguments to follow can take on most accounts of intuition. All that is needed is that we observe the epistemic role intuition plays in so much of contemporary philosophy: intuition is commonly taken to be a source of

\footnotetext{
${ }^{9}$ For example, Bealer [1998], Pust [2000], Grundmann [2007] and Sosa [2007] each identify intuition with a seeming of a particular sort, where seemings are genuine mental states. (Though Sosa identifies this kind of seeming with a particular sort of attraction to assent). Others disagree. For example, and Williamson [2004] take intuitions to be judgments (see also Goldman and Pust [1998, 179]); Lewis [1983] suggests that intuitions are simply beliefs; Earlenbaugh and Molyneux [2009] claim that they are inclinations to believe; and van Inwagen [1997, 309] and Lynch [2005] hold that they are either beliefs or inclinations to believe.
} 
evidence that justifies beliefs. ${ }^{10,11}$ It should also be noted that commitment to there being this kind of mental state does not entail a commitment to the more robust thesis that there is a unique cognitive faculty which is itself solely responsible for every tokening of the type. Nothing so substantial is either assumed or implied.

Additionally, in what follows I will often speak of propositions being justified and (equivalently) of thinkers having justification to believe, or justification for, certain propositions. To say that a proposition $p$ is justified (for some thinker) is to say that one has ultima facie justification to believe $p$, whether or not one in fact believes it. I will not be concerned with the related epistemic properties of having mere prima facie justification or of having some justification; rather, my sole concern is with the sort of justification that is needed for one to have a justified belief.

Now we can address the target argument against intuitions. The employment of intuitions by philosophers has its detractors, those who claim intuition is deficient and ill-suited to philosophy's aims. Such claims have been made on various grounds, but the particulars of these grounds needn't concern us. ${ }^{12}$ Our concern is with what help considerations of epistemic selfdefeat might offer defenders of intuition vis-a-vis its detractors who argue in the following way:

\footnotetext{
${ }^{10}$ Issues of defeasibility and the relativizaiton of justification to believers and to beliefs that share the same content as specific tokens of intuition will be left implicit.

${ }^{11}$ Earlenbaugh and Molyneux [2009] argue against the thesis that intuitions are treated as evidence by philosophers. Although their arguments are worthy of response, the denial of their thesis will remain a presupposition of my paper.

${ }^{12}$ For example, there are Benacerraf-style explanatory worries about intuition since intuition is thought to yield knowledge of abstract facts despite the fact that intuitions are not plausibly causally dependent on such facts. This makes the supposed reliability of intuition seem unexplainable; and if such reliability is unexplainable, it has seemed to some that intuition could not be, or at least should not be thought to be, reliable. (For concerns of this sort see Field [1989, 230-239], Boghossian [2000] and [2001], Kitcher [2000, 75], and Devitt [2005, section 3-4].) This is what we might call philosophical grounds for thinking intuition unreliable. But there are also empirical grounds stemming from the recent work of experimental philosophers whose studies are said to show that intuition's deliverances are sensitive to features of one's situation that have nothing to do with the truth of what is intuited (e.g., the ordering of thought experiments considered, cultural biases, educational background, affective biases), thereby giving us reason to think intuition unreliable. (See Weinberg et al. [2001], Nichols et al. [2003], Alexander and Weinberg [2007, esp. 62-63], and Swain et al. [2008] for some relevant studies and discussions motivating this concern with intuition's reliability.)
} 
$(\neg \mathrm{Ri})$ Intuition is not reliable.

and from $(\neg \mathrm{Ri})$ infer:

( $\neg \mathrm{Si}$ ) Intuition is not a source of evidence that justifies beliefs.

The inference surely seems valid, and it likewise seems as if one who had justification for $(\neg \mathrm{Ri})$, and inferred $(\neg \mathrm{Si})$ from $(\neg \mathrm{Ri})$ would thereby come to have justification for $(\neg \mathrm{Si})$. But for this to be the case, it seems that one would need justification for:

$(\mathrm{Sx} \rightarrow \mathrm{Rx})$ Something is a source of evidence that justifies beliefs only if it is reliable.

Otherwise it would be unclear just how one could come to have justification for $(\neg \mathrm{Si})$ solely on the basis of having justification for $(\neg \mathrm{Ri})$. (Sx $\rightarrow \mathrm{Rx})$ expresses a necessary condition sources of evidence must satisfy if they are to justify beliefs. ${ }^{13}$ Let us call this argument from $(\mathrm{Sx} \rightarrow \mathrm{Rx})$ and $(\neg \mathrm{Ri})$ to ( $\neg \mathrm{Si}$ ), 'the Unreliability Argument'.

Here the defender of intuition is in a ripe place to employ the BealerBonJour-Pust reductio strategy, which, as noted above, consists of two steps. The first step is conciliatory, for it grants the following:

Dialectical Assumption (DA): The premises of the Unreliability Argument are both true and justified.

Of course, the defender of intuitions thinks (DA) is false: for he thinks that, at least, $(\neg \mathrm{Ri})$ is false and unjustified, but he provisionally grants it for the purpose of defusing the Unreliability Argument through considerations of epistemic self-defeat. ${ }^{14}$ The second step is confrontational, for it argues that

Epistemic Self-Defeat (ED): The Unreliability Argument is epistemically self-defeating.

\footnotetext{
${ }^{13}$ Reliabilist and other externalist stances on justification entail $(\mathrm{Sx} \rightarrow \mathrm{Rx})$. We will discuss the threat $(\neg \mathrm{Ri})$ poses independently of $(\mathrm{Sx} \rightarrow \mathrm{Rx})$ at close of this section.

${ }^{14}$ It may not be apparent why (DA) includes considerations of justification, for the above summary of the Bealer-BonJour-Pust strategy did not clearly include such considerations. The reason is that it is no concession to an opponent to grant the truth of some proposition $p$ without also granting justification for it at least where $p$ is to serve as a premise in some chain of reasoning. For the purpose of reasoning from premises is the transmission of justification from premises to conclusion, and no reasoning can succeed at transmitting justification to a conclusion without having justified premises.
} 
For example, following Pust, one might argue that the Unreliability Argument is epistemically self-defeating because $(\mathrm{Sx} \rightarrow \mathrm{Rx})$ is an epistemic norm and as such our justification for $(\mathrm{Sx} \rightarrow \mathrm{Rx})$ depends upon intuition being a source of evidence that provides us with justification for it; or following Bealer, one might argue that the Unreliability Argument is epistemically self-defeating because of the role intuition plays in concept application. If either of these thoughts are correct, then the Unreliability Argument is epistemically self-defeating.

To see that (ED) follows from these considerations note that each one implies the following conditional because each entails a certain justificatory dependence relation between the premises and the conclusion of the Unreliability Argument:

(1) If $(\neg \mathrm{Si})$ is justified, then $(\mathrm{Sx} \rightarrow \mathrm{Rx})$ is not justified.

And given (DA) we have:

(2) $(\mathrm{Sx} \rightarrow \mathrm{Rx})$ is justified.

Together these entail:

(3) $(\neg \mathrm{Si})$ is not justified.

That is, we lack justification to believe that intuition is not a source of evidence that justifies beliefs. Thus (ED) follows if either Bealer or Pust's considerations are correct. But (ED) also follows if BonJour is correct that intuition is required if one is to acquire justification for the conclusion of an argument on the basis of the premises from which it was inferred. For if this is right, and if our justification for $(\neg \mathrm{Si})$ depends on some inference from justified premises, then the following conditional is true:

(4) If $(\neg \mathrm{Si})$ is justified, then $(\neg \mathrm{Si})$ is not justified.

which also entails (3). The result, then, is that even if (DA) were true, we would lack justification for $(\neg \mathrm{Si})$, i.e., we would not have justification to believe intuition lacks evidentiary value.

Such a result might appear to be a victory for the defender of intuitions for the defender has been able to show that from premises his opponent 
accepts (namely, (DA)), it follows that he lacks justification to believe $(\neg \mathrm{Si}) .{ }^{15}$ But this is only an apparent or, at best, a partial victory for those who think intuitions evidentially valuable. The problem is that the defender of intuitions thinks that we are justified in thinking that intuition is a source of evidence that justifies beliefs, i.e., ( $\mathrm{Si}$ ) is justified. But this claim can be justified only if we lack justification to believe that intuition is unreliable. Thus, if there is sufficient reason to think $(\neg \mathrm{Ri})$ true, then $(\mathrm{Si})$ cannot be justified and the fact that the Unreliability Argument is epistemically selfdefeating fails to show otherwise.

In order to locate the lingering problem facing defenders of intuition it helps to put ourselves in their shoes by taking (DA) as an assumption. In making this assumption one puts oneself in a position to carry out the following conditional argument:

(5) $(\mathrm{Sx} \rightarrow \mathrm{Rx})$ and $(\neg \mathrm{Ri})$ are each justified. (assumption)

(6) If $(\mathrm{Sx} \rightarrow \mathrm{Rx})$ and $(\neg \mathrm{Ri})$ are justified and one competently deduces $(\neg \mathrm{Si})$ from $(\mathrm{Sx} \rightarrow \mathrm{Rx})$ and $(\neg \mathrm{Ri})$, then $(\mathrm{Si})$ is not justified. (premise, discussed below)

(7) $(\mathrm{Si})$ is not justified. (from (5) and (6))

Thus, given that the defenders have competently deduced $(\neg \mathrm{Si})$ from $(\mathrm{Sx} \rightarrow \mathrm{Rx})$ and $(\neg \mathrm{Ri})$, what follows from our assumption of $(5)$ is:

(8) If $(\mathrm{Sx} \rightarrow \mathrm{Rx})$ and $(\neg \mathrm{Ri})$ are justified, then $(\mathrm{Si})$ is not justified. (conditional reasoning from (5)-(7))

Accordingly, if (DA), and thus (5), is correct, what follows from (8) is:

(9) $(\mathrm{Si})$ is not justified.

Will the defender of intuitions concede (9)? That is, will the defender grant that he is not justified in thinking intuition is a source of evidence that justifies beliefs? Of course not. The defender will respond by pointing out that (DA) is just an assumption that is neither true nor justified. But that's the

\footnotetext{
${ }^{15}$ This is clearly the case in the argument from (1) and (2) to (3). Whether or not this is the case in the argument from (4) to (3) depends on the correctness of BonJour's conviction that (i) in order to be justified in believing the conclusion of an argument from premises one must have reason to think the premises make the conclusion at least likely to be true, and that (ii) intuition alone can give one such a reason.
} 
point: showing that one's opponent's argument is epistemically self-defeating is not a sufficient defense of intuition vis-a-vis the Unreliability Argument. Rather, arguments against (DA) must be given if there is some (undefeated) reason to think it's true. Thus, the general lesson in the offing is that there is a limit on the usefulness to which we can put the observation that an argument is epistemically self-defeating for there are at least some epistemically self-defeating arguments, such as the Unreliability Argument, that can epistemically undermine one's position.

There are some concerns one might have about the above conditional proof for (8). In that argument much turns on premise (6) and this is something that opponents of intuition might not accept, perhaps because the only reasons for accepting it are based in some way on intuition. But that's fine. The point here is to see a problem defenders of intuition face, and they will likely esteem both (6) and the following arguments I have to offer on its behalf.

I take (6) to follow from (i) the assumption that the contradictory of any justified proposition is itself unjustified, ${ }^{16}$ and (ii) a reasonable deductive closure principle for justification. ${ }^{17}$ Such a closure principle will resemble the following:

Closure. If premises $P_{1} \ldots P_{n}$ are justified and one competently deduces $C$ from them, then $C$ is justified. ${ }^{18}$

\footnotetext{
${ }^{16}$ One might wish to emend (i) in the following way:

$\left(\mathrm{i}^{*}\right)$ The contradictory of any justified proposition that is justified in virtue of being deduced from other justified propositions is itself unjustified.
}

This qualification may be added to avoid concerns about Uniqueness: the thesis that one's total evidence determines a unique rational doxastic attitude towards any proposition. For even if Uniqueness is false and it is therefore sometimes epistemically permissible to either believe or not believe $p$ on one's total evidence, it remains implausible to think that when one's total evidence entails $p$ and one has deduced $p$ from one's evidence that it can be epistemically permissible to not believe $p$. See White [2005] for a defense of Uniqueness and Brueckner and Bundy [2011] for criticism.

${ }^{17}$ I do not take (i) to extend to inconsistent propositions generally since recognition that two propositions are inconsistent may be well beyond one's ken. I do not think this the case with contradictions because their form ( $p$ and not- $p$ ) makes their inconsistency plain, at least for my target audience.

${ }^{18}$ This closure principle gives a sufficient condition for when one has justification to believe, as opposed to when one justifiedly believes, the conclusion of a deductive inference. If our concern were with justified belief in the conclusion we would have to strengthen 
Yet certain qualifications are needed if Closure is to retain its plausibility in the face of counterexamples, and one might worry that epistemically selfdefeating arguments constitute one type of counterexample that a reasonable closure principle must take account of. If so, then, provided the Unreliability Argument is epistemically self-defeating, (6) could not be taken to follow from Closure. However, it is unclear that epistemically self-defeating arguments do threaten Closure, for it seems plausible to think that it is impossible for the premises of any epistemically self-defeating argument to remain justified when one has competently deduced the conclusion from its premises, especially when one has recognized the self-defeating character of the argument. That is, in such cases one loses their justification to believe the premises, thereby avoiding the threat to Closure.

But even if Closure needs some qualification to account for epistemically self-defeating arguments, (6) need not come into question. For one could also defend (6) by arguing that it follows from:

Quasi-Closure. If premises $P_{1} \ldots P_{n}$ are justified and one competently deduces $C$ from them, then $\neg C$ is not justified.

The idea behind this principle is that competent deduction from justified premises can preclude certain claims from being justified, namely, the contradictory of what was deduced. Quasi-Closure is quite plausible for its denial implies that $\neg C$ may be justified when propositions that clearly entail that $\neg C$ is false are themselves justified. But this does not seem possible, for in such a case one would have a rebutting defeater for $\neg C$ which is inconsistent with one having justification for $\neg C{ }^{19}$ So (6) seems reasonably safe, thus securing our earlier conclusion that observing the epistemically self-defeating character of the Unreliability Argument fails to preserve one's justification for $(\mathrm{Si})$ if there is sufficient reason to think $(\mathrm{Sx} \rightarrow \mathrm{Rx})$ and $(\neg \mathrm{Ri})$ are true. ${ }^{20}$

the antecedent of Closure so as to include justified belief in the premises, belief in the conclusion, and that one's belief in the conclusion satisfies whatever epistemic basing constraints there are, and perhaps other conditions as well to help deal with the lottery and preface paradoxes.

${ }^{19}$ Roughly, a defeater for $p$ is something that prevents one from having ultima facie justification for $p$. One has a rebutting defeater for $p$ when one either believes that $p$ is false or has an undefeated reason to believe that $p$ is false. Surely if one had (undefeated) justification for premises that clearly entailed $\neg p$, then one would have a reason to believe that $p$ is false.

${ }^{20} \mathrm{~A}$ referee pointed out to me that some might think that (8) cannot be justified if we 
Now, there is a further argument for this same conclusion, one which does not depend on the externalist conviction that $(\mathrm{Sx} \rightarrow \mathrm{Rx})$ obtains nor the aforementioned Closure and Quasi-Closure principles. This argument capitalizes on the relationship between justification and reliability. For even if the reliability of a source of evidence is not necessary for that source to generate justification, justification for thinking a source unreliable is enough to prevent that source from generating (undefeated) justification, and thereby prevents that source from justifying beliefs. Thus:

(10) If ( $\neg \mathrm{Ri}$ ) is justified, then ( $\mathrm{Si}$ ) is not justified.

Consider what the denial of (10) would amount to: the admission that one could have undefeated justification to believe that intuition is unreliable and also have undefeated justification to believe that it is a source of evidence that justifies beliefs. But intuition cannot justify any belief when one has undefeated reason to think it unreliable since undefeated justification for $(\neg \mathrm{Ri})$ constitutes an undercutting defeater for every claim supported by intuition, thereby preventing intuition from justifying any belief. ${ }^{21}$ This situation is analogous to the use of sense perception in a demon world when one has justification to believe that one is in a demon world. For being in a demon world makes sense perception unreliable, and so if one were justified in thinking they inhabited such a world, they would not be justified in regarding sense perception as a source of evidence able to justify beliefs.

Again, we are in a position to see the limitations of defending intuition by appealing to epistemic self-defeat. For if we grant (DA), then we thereby grant that $(\neg \mathrm{Ri})$ is justified, which in conjunction with (10) implies (9),

are working in a context that takes $(\mathrm{Sx} \rightarrow \mathrm{Rx})$ and $(\neg \mathrm{Ri})$ for granted because they clearly imply ( $\neg \mathrm{Si}$ ) and, presumably, one depends on intuition for their justification to believe (6). Notice, however, that one's actual justification for (6) is not impugned by the fact that one has assumed (5) for a conditional proof. Conditional proofs are like ordinary proofs in that one is allowed to include in the proof anything one has (undefeated) justification to believe as a premise. In the present conditional proof the assumption is (5) whereas the premise the defender of intuitions takes themselves, or should take themselves as I argue, to have justification for is (6). Thus, one's actual justification for ( $\mathrm{Si}$ ) remains intact-provided that one does not actually acquire justification for both $(\mathrm{Sx} \rightarrow \mathrm{Rx})$ and $(\neg \mathrm{Ri})$, thereby making them more than mere assumptions.

${ }^{21}$ Roughly, one has an undercutting defeater for $p$ if one either believes or has reason to believe that their (supposed) source of justification for $p$ does not make $p$ likely to be true. And if one has justification for $(\neg \mathrm{Ri})$ then one does have such a reason for any proposition whose only support is its being the content of an intuition. 
i.e., they imply that one lacks justification to believe intuition is a source of evidence that justifies beliefs. Thus, since the defender of intuitions must endorse (10), (DA) poses a direct threat if, as I keep emphasizing, there is sufficient reason to think it true. But more specifically, what the argument of the previous paragraph shows us is that it does not matter how things pan out with respect to $(\mathrm{Sx} \rightarrow \mathrm{Rx})$ for there is a direct threat to intuitions so long as there is sufficient reason to think $(\neg \mathrm{Ri})$ true. Thus the only adequate defense of intuitions is to undermine whatever reasons there might be to think $(\neg \mathrm{Ri})$ true. Appealing to considerations of epistemic-self defeat cannot help. ${ }^{22}$

\section{Conclusion}

In conclusion, we have seen that intuitions cannot be adequately defended merely by employing the strategy of Bealer, BonJour, and Pust. The defenders of intuition have to "get their hands dirty," dealing with whatever reasons there might be for thinking that $(\neg \mathrm{Ri})$ is true. But we have also seen that if the Unreliability Argument is epistemically self-defeating, then opponents of intuition cannot be justified in believing that intuition is not a source of evidence that justifies beliefs. Thus, if opponents are to be justified in their rejection of intuition's evidentiary value, they must undermine whatever reasons there are for thinking the Unreliability Argument epistemically self-defeating, i.e., they must undermine the arguments of Bealer, BonJour, and Pust at the very least. ${ }^{23}$

\footnotetext{
${ }^{22}$ And by undermining $(\neg \mathrm{Ri})$ we thereby undermine the further claim that is part of (DA), namely, that we have (undefeated) justification for $(\neg \mathrm{Ri})$.

${ }^{23}$ In this paper we have focused on the epistemically self-defeating character of the Unreliability Argument and have been dealing with 'intuition' in a non-discriminatory way by ignoring the possibility that, say, intuitions in some domains are reliable while others are not. For instance, perhaps when it comes to math and logic, intuition is reliable but when it comes to metaphysics and ethics it is not. It must be observed that any attempt to defend the Unreliability Argument in this manner must alter its premises and conclusion in some way so that the conclusion does not indict all uses of intuition. The particulars, of course, depend on just how one attenuates their opposition to intuition. Notice that any emended argument will have a conclusion like the following:
}

(11) Intuitions of domain D are not a source of evidence that justifies beliefs.

And given that (11) is itself an epistemological proposition, it seems that any argument in support of it will have to employ some general epistemological principle (akin to ( $\mathrm{Sx} \rightarrow \mathrm{Rx})$ ). 
But there is a final lesson to tease from our inquiry, one that follows from the previous two: if one has undefeated reason to think $(\neg \mathrm{Ri})$ is true and undefeated reason to think (ED) is true, then skepticism with respect to intuition's evidentiary value follows. That is, one is not justified in thinking that intuition is a source of evidence that justifies beliefs nor is one justified in thinking that intuition is not a source of evidence that justifies beliefs. This would be surprising for one would think that if the Unreliability Argument suffered from epistemic self-defeat the challenge to intuitions would dissolve with it. But no such result follows so long as $(\neg \mathrm{Ri})$ remains undefeated. Moreover, one would think that if we were justified in thinking that intuition is unreliable, we would be justified in thinking it lacks justificatory power. But, again, no such result follows if the Unreliability Argument is epistemically self-defeating. ${ }^{24,25}$

\section{Bibliography}

Alexander, J. and J. Weinberg. 2007. "Analytic Epistemology and Experimental Philosophy," Philosophy Compass, vol. 2: 5680 .

Bealer, G. 1992. "The Incoherence of Empiricism," Proceedings of the Aristotelian Society, Supplementary Volume 66: 99-138.

Bealer, G. 1998. "The Autonomy and Authority of Philosophy,"

And, as Pust and Bealer have pointed out, it is difficult to see how else one could justify any such principle without at least some epistemological intuitions having evidentiary value. If this is right, then we could not be too restrictive concerning which intuitions have evidentiary value for whatever reasons there are for thinking, say, moral and metaphysical intuitions are unreliable (e.g., pervasive disagreement among certain groups) are also reasons for thinking that epistemological intuitions are unreliable. So, in the end, one might expect non-skeptical opposition to intuition to be quite moderate, allowing for quite a range of intuitions. But assessing the various arguments and positions one might take concerning intuition's reliability and justificatory power goes beyond the concern of this paper, which was to assess the usefulness of the self-defeat argument for intuition vis-a-vis the Unreliability Argument.

${ }^{24}$ Ironically, this is a fact we can appreciate only if intuitions have evidentiary value given that I've relied on various intuitions to justify my arguments in this paper.

${ }^{25}$ Special thanks are owed to Michael Lynch, Patrick Greenough, and Joel Pust who provided me with detailed feedback on an early draft. Further thanks are owed to Donald Baxter, John Troyer, an anonymous referee at Philosophical Studies, and audiences at the University of Connecticut and Notre Dame. 
in Rethinking Intuition: The Psychology of Intuition and Its Role in Philosophical Inquiry, M. De Paul and W. Ramsey (eds.), New York: Rowman \& Littlefield Publishers: 201-239.

Bergmann, M. 2006. Justification Without Awareness, Oxford: Oxford University Press.

BonJour, L. 1998. In Defense of Pure Reason, Cambridge: Cambridge University Press.

BonJour, L. 2002. Epistemology: Classic Problems and Contemporary Responses, Lanham: Rowman \& Littlefield.

Boghossian, P. 2000. "Knowledge of logic," in New Essays on the A Priori, P. Boghossian and C. Peacocke (eds.), Oxford: Oxford University Press: 229-254.

Boghossian, P. 2001. "Inference and insight," Philosophy and Phenomenological Research, vol. 63: 633-640.

Brueckner, A. and A. Bundy. 2011. "On "Epistemic Permissiveness"," Synthese, on-line first.

Cullison, A. 2010. "What Are Seemings?" Ratio XXIII: 260-274.

Devitt, M. 2010. Putting Metaphysics First, Oxford: Oxford University Press.

Devitt, M. 2005. "There is No A Priori," in Contemporary Debates in Epistemology, M. Steup and E. Sosa (eds.), Oxford: Blackwell: 105-114.

De Paul, M. and W. Ramsey. 1998. Rethinking Intuition: The Psychology of Intuition and Its Role in Philosophical Inquiry, New York: Rowman \& Littlefield Publishers.

Earlenbaugh J. and B. Molyneux. 2009. "Intuitions are inclinations to believe," Philosophical Studies, 145:89-109.

Field, H. 1989. Realism, mathematics, and modality, Oxford: Basil Blackwell.

Foley, R. 1993. Working without a Net: A Study of Egocentric Epistemology, Oxford: Oxford University Press.

Foley, R. 2001. Intellectual Trust in Oneself and Others, Cambridge: Cambridge University Press. 
Gendler, S. and J. Hawthorne, Oxford Studies in Epistemology, Volume 1, Oxford University Press: Oxford.

Goldman, A. 2007. "Philosophical Intuitions: Their Target, Their Source, and Their Epistemic Status," Grazer Philosophische Studien 74: 1-26.

Goldman, A. and J. Pust. 1998. "Philosophical Theory and Intuitional Evidence," Rethinking Intuition: The Psychology of Intuition and Its Role in Philosophical Inquiry, M. De Paul and W. Ramsey (eds.), New York: Rowman \& Littlefield Publishers: 179-197.

Grundmann, T. 2007. "The Nature of Rational Intuitions and a Fresh Look at the Explanationist Objection," Grazer Philosophische Studien 74: 69-87.

Kornblith, H. 2002. Knowledge and its Place in Nature, Oxford: Oxford University Press.

Kitcher, P. 2000. "A Priori Knowledge Revisited," in New Essays on the A Priori, P. Boghossian and C. Peacocke (eds.), Oxford: Oxford University Press: 65-91.

Lewis, D. 1983. Philosophical Papers, vol. 1. Oxford: Oxford University Press.

Lynch, M. 2005. "Trusting Intuition," Truth and Realism, M. Lynch and P. Greenough (eds.), Oxford: Oxford University Press: 227-238.

Lynch, M. and P. Greenough, Truth and Realism, Oxford: Oxford University Press.

Nichols, S., Stich, S., and Weinberg, J. 2003. "Meta-skepticism: Meditations on ethno-epistemology," in The Skeptics, S. Luper (ed.), Aldershot, U.K: Ashgate Publishing: 227-247.

Pryor, J. Forthcoming. "When Warrant Transmits," to appear in Wittgenstein, Epistemology and Mind: Themes from the Philosophy of Crispin Wright, Annalisa Coliva (ed.), Oxford.

Pust, J. 2000. Intuitions as Evidence, New York: Garland Publishing, Inc. 
Pust, J. 2001. "Against Explanationist Skepticism Regarding Philosophical Intuitions," Philosophical Studies, 106: 227-258.

Sosa, E. 2007. A Virtue Epistemology: Apt Belief and Reflective Knowledge, Oxford: Oxford University Press.

Swain, S., Alexander, J., and Weinberg, J. 2008. "The instability of philosophical intuitions: Running hot \& cold on truetemp," Philosophy and Phenomenological Research, vol. 76: 138-155.

van Inwagen, P. 1997. "Materialism and Psychological-Continuity Account of Personal Identity," Philosophical Perspectives, vol. 11: 305-19.

Weinberg, J., Nichols, S., and Stich, S. 2001. "Normativity and epistemic intuitions," Philosophical Topics, vol. 29: 429-460.

White, R. 2005. "Epistemic Permissiveness," Philosophical Perspectives, vol.19: 445-459.

Williamson, T. 2000. Knowledge and its Limits, Oxford: Oxford University Press.

Williamson, T. 2004. "Philosophical 'Intuitions' and Skepticism about Judgement," Dialectica 58: 109-153. 